\title{
МОДЕЛЬ ОЦЕНКИ УСТОЙЧИВОСТИ БИЗНЕС-ПРОЦЕССОВ ДЕРЕВООБРАБАТЫВАЮЩЕГО ПРЕДПРИЯТИЯ ВЬЕТНАМА
}

\author{
(C) 2020 Чан Тхи Тхань Тхюи \\ Высшая инженерно-экономическая школа \\ Санкт-Петербургский политехнический университет Петра Великого (СПбПУ), \\ Россия, Санкт-Петербург \\ E-mail: thuytrannvcard@gmail.com \\ (c) 2020 Дегтерева Виктория Анатольевна \\ доктор экономических наук, профессор, Высшая инженерно-экономическая школа \\ Санкт-Петербургский политехнический университет Петра Великого (СПбПУ), \\ Россия, Санкт-Петербург \\ E-mail: degtereva_va@spbstu.ru
}

Процесс взаимодействия промышленного предприятия и внешней среды является двунаправленным. Множество научных исследований посвящено анализу специфики влияния внешней среды на промышленные предприятия, в то время как, анализу влияния промышленного предприятия на внешнюю среду посвящено исключительно крайне узкое направление экологических исследований. В рамках данного исследования рассматривается процесс влияния производственной деятельности деревообрабатывающего промышленного предприятия на внешнюю среду. Результатом исследования является нечетко-множественная модель оценки данного влияния, в виде агрегированного показателя устойчивости бизнес-процессов деревообрабатывающего предприятия Вьетнама.

Ключевые слова: устойчивое развитие, бизнес-процессы, устойчивость, нечеткая логика, деревообрабатывающая промышленность, Вьетнам.

Для целей оценки устойчивости бизнеспроцесса необходимо определить вектора воздействия бизнес-процесса на окружающую среду. Как уже было установлено ранее, доминирующее влияние деревообрабатывающее предприятие оказывает на лесное хозяйство в рамках потребления леса как базового сырья или материала для целей производства конечной продукции. Однако, помимо процесса потребления, предприятия деревообрабатывающей промышленности неизбежно формируют значительный объем отходов производства, неразумная утилизация которых может оказывать неизменно отрицательное воздействие на окружающую среду. Можно выделить следующие основные вектора вредоносного воздействия на окружающую среду со стороны деревообрабатывающих промышленных предприятий:

1. Выбросы в атмосферу продуктов сгорания топлива в рамках процесса утилизации отходов производства. К основным группам данных веществ можно отнести $\mathrm{CO}_{2}, \mathrm{NO}_{2}$ и сажу. Также, в рамках данного воздействия на атмосферу можно выделить выбросы летучих веществ в рамках процесса ламинированния, прессова- ния и склеивания, а также защитной обработке древесины.

2. Сброс производственных и хозяйственно-бытовых сточных вод в почву и водоемы.

3. Санкционированное и несанкционированное размещение твердых бытовых отходов.

4. Воздействие на экологическую среду за счет потребления лесных ресурсов в качестве материалов и сырья для производства конечной продукции.

Сила и характер влияния каждого из выделенных векторов воздействия деревообрабатывающего промышленного предприятия на окружающую среду могут быть выражены совокупностью уникальных показателей, а именно:

1. Выбросы в атмосферу в первую очередь могут быть дифференцированы в соответствии с типом операции и соответствующим оборудованием, реализующим данную операцию. Рассмотрим последовательно основные операции, реализуемые деревообрабатывающим промышленным предприятием:

а. Механическая обработка древесины. Данный процесс реализуется на подавляющем большинстве деревообрабатывающих промыш- 
ленных предприятий, а ключевым оборудованием, обеспечивающим реализацию данного процесса, являются деревообрабатывающие станки и циркулярные станки. Основным типом выбросов в данном случае выступает древесная пыль. Основным параметром классификации древесной пыли является крупность. Источником выброса древесной пыли в атмосферу выступают пылеулавливающие сооружения. Количество выбрасываемой пыли измеряется в тоннах в год (т/год) и измеряется как скорректированное (разделенное на 10 в третьей степени) произведение удельного показателя пылеобразования на единицу деревообрабатывающего оборудования, измеренного в килограммах в час (кг/час), и времени работы технологического оборудования, измеренного в часах в год (час/год). Принцип калькуляции данного параметра сохраняется для большинства видов обрабатываемой продукции, однако неизбежна детализация. В частности, объем древесной пыли, образующийся при производстве технологической щепы рассчитывается как скорректированное (разделенное на 10 в пятой степени) произведение времени работы технологического оборудования, измеренного в часах в год (час/ год), содержания пыли в щепе, измеряемого в процентах (\%) и расчетной часовой производительности пневмотранспорта, измеренного в килограммах в час (кг/час). Консолидированный показатель может быть универсализирован, условным обозначением можно принять аббревиатуру МОД, а единицами измерения - тонны в год. При этом вектор влияния данного показателя на результирующий является отрицательным (при увеличении данного показателя устойчивость бизнес-процессов деревообрабатывающего предприятия снижается).

b. Склейка древесины и шпона. Данный процесс реализуется при ламинированнии, производстве ДСП и иных производственных процессах с применением клеенамазывающих вальцов и прессов. Основные загрязняющие атмосферу выбросы в данном случае представлены фенолом, формальдегидом, аммиаком и метанолом. При производстве ДСП объем свободного формальдегида и фенола, измеренного в килограммах в час (кг/час), рассчитывается как скорректированное (разделенное на 10 в третьей степени) произведение расхода смолы, измеренного в килограммах в час (кг/час), содержания свободного формальдегида и фенола в составе смолы, измеряемого в процентах (\%) и коэффициента поступления свободного формальдегида и фенола в окружающую среду, как правило равного 0,4. При производстве фанеры данный показатель рассчитывается идентичным образом, однако коэффициент поступления свободного формальдегида и фенола в окружающую среду принимается равным 0,5. Также, данные выбросы характерны для мебельного производства. Расчет данного показателя при нанесении и облицовке натурального и синтетического шпона идентичен вышеприведенному, однако коэффициент поступления свободного формальдегида и фенола в окружающую среду принимается равным 0,3. В рамках процесса пропитки или ламинированния бумаги также рассчитывается альтернативный показатель, однако коэффициент поступления свободного формальдегида в окружающую среду принимается равным 0,1 . Также данные вещества выделяются в рамках отделки древесины при использовании лаконаливных машин и лакораспылительных кабин, сушке древесины при использовании сушильных камер и приготовлении связующих веществ. Однако, данным воздействием на окружающую среду можно пренебречь, ввиду незначительности объёмом выбросов.

Консолидированный показатель может быть универсализирован, условным обозначением можно принять аббревиатуру СДШ, а единицами измерения - килограммы в час. При этом вектор влияния данного показателя на результирующий является отрицательным (при увеличении данного показателя устойчивость бизнес-процессов деревообрабатывающего предприятия снижается).

2. Сброс сточных вод в водоемы и в почву не менее актуальная проблема для деревообрабатывающей промышленности. Степень вредоносного воздействия в данном случае может быть дифференцирована в соответствии с составом сбрасываемых сточных вод. Основными загрязняющими веществами в рамках деревообрабатывающей промышленности являются сульфаты, лигнины, смолистые вещества и азот. Однако, вектор воздействия данных веществ на водные и почвенные ресурсы соразмерен и однонаправлен, более того, крайне редко данные выбросы производятся изолированно. Таким образом, в данном случае может быть предложен один консолидированный показатель, условным обозначением которого можно принять аббре- 
виатуру ССВП, а единицами измерения - килограммы в час. При этом вектор влияния данного показателя на результирующий является отрицательным (при увеличении данного показателя устойчивость бизнес-процессов деревообрабатывающего предприятия снижается).

3. Санкционированное и несанкционированное размещение твердых бытовых отходов потенциально оказывает наиболее значимое влияние на окружающую среду. Под производственными отходами стоит понимать остатки сырья и материалов, которые образовались в рамках производственной деятельности деревообрабатывающего предприятия и не могут быть далее использованы в производственном процесс. Также, к отходам в данном случае можно отнести изделия из древесины, утратившие свои потребительские свойства и приготовленные к утилизации. Безусловно, деревообрабатывающая промышленность является одной из наиболее эффективных с точки зрения использования отходов производства, так как отходы лесопромышленных комплексов и деревообрабатывающих комбинатов зачастую являются основным сырьем для производства щепы и ДСП. Существует множество классификаций производственных отходов в деревообрабатывающей промышленности, базовой из которых является разделение на основные и побочные. Однако, в рамках данного исследования принято решение введения единого консолидированного показателя, отражающего данное влияние со стороны деревообрабатывающей промышленности на окружающую среды. Данный выбор обусловлен тем, что базовой технологией утилизации данного типа отходов, неизменно оказывающей влияние на окружающую среду, является захоронение. Консолидированный показатель может быть универсализирован, условным обозначением можно принять аббревиатуру РТБО, а единицами измерения - тонны в год. При этом вектор влияния данного показателя на результирующий является отрицательным (при увеличении данного показателя устойчивость бизнес-процессов деревообрабатывающего предприятия снижается).

4. Воздействие на экологическую среду за счет потребления лесных ресурсов в качестве материалов и сырья для производства конечной продукции, является наиболее диалектичным типов воздействия. Диалектика в данном случае выражается в том, что интенсивность использо- вания базового типа ресурсов в деревообрабатывающей промышленности в первую очередь является результатом повышения интенсивности спроса, а следовательно повышения экономического эффекта от основной деятельности деревообрабатывающего промышленного предприятия. Однако, при этом именно данный процесс продуцирует сверхпотребление базового природного ресурса, что в свою очередь крайне негативно сказывается на состоянии окружающей среды. Следовательно, интенсивный рост потребления базового ресурса должен неизменно сопровождаться интенсивным ростом восстановления данного ресурса на природном уровне. Одним из наиболее базовых механизмов данного восстановления является целевое приращение лесного массива, выраженное объемом посадок. Таким образом, консолидированный показатель в данном случае будет представлять из себя отношение восстановленного базового ресурса за период к объему потребленного ресурса за идентичный период. Консолидированный показатель может быть универсализирован, условным обозначением можно принять аббревиатуру ВЛР, а единицами измерения - проценты в год. При этом вектор влияния данного показателя на результирующий является положительным (при увеличении данного показателя устойчивость бизнес-процессов деревообрабатывающего предприятия увеличивается).

Представленную классификацию можно разделить на три уровня консолидации, верхним из которых является результирующий показатель устойчивости бизнес-процессов деревообрабатывающего предприятия, а нижним - конкретные показатели, отражающие тот или иной вектор воздействия. Исследуемое влияние также может быть распределено с точки зрения удельного вес. Данное распределение носит неравномерный характер, и может быть структурировано с иерархической точки зрения. Для данных целей может быть использован концептуальный подход Фишберна, который позволяет равномерно распределить удельный вес между показателями в соответствии с линейно убывающей функцией. Для целей реализации данного подхода в первую очередь необходимо сформировать иерархию показателей в соответствии с силой их влияния. Для данных целей может быть использован последовательный алгоритм бинарного сопоставления. Визуализация результатов применения данного алгоритма представле- 
на на рисунке 1.

Как можно видеть на рисунке, наиболее значимое влияние оказывает показатель, отражающий воздействие деревообрабатывающего предприятия на экологическую среду за счет потребления лесных ресурсов в качестве материалов и сырья для производства конечной продукции. В первую очередь это обусловлено тем, что это единственный показатель требующей реализации активного подхода к реализации и компенсации последствий, при этом значимость данного процесса возрастает параллельно приращению экономического эффекта деревообрабатывающего предприятия. Остальные показатели отражают непосредственное воздействие деревообрабатывающего предприятия на экологическую среду. Результирующее распределение удельного веса представлено на рисунке 2 .

Используемая система показателей не в полной мере может быть конвертирована в интегральный показатель устойчивости бизнеспроцессов деревообрабатывающего предприятия. В первую очередь это обусловлено дифференциацией способов и инструментов оценки используемых показателей. Более того, исследуемые показатели являются комплексными, что определяет целесообразность использования нечетких интервалов оценки, так как данные интервалы дают возможность учитывать степень уверенности субъекта в принадлежности состояниям показателя тому или иному интервалу. Следовательно, наиболее целесообразным к моделированию в рамках данного исследования является нечеткомножественный подход. Недосекиным А. О. был предложен универсальный алгоритм построения нечетко-множественных моделей оценки подобных комплексных социально-экономических явлений [13]. В соответствии с данным алгоритмом, по результатам идентификации ключевых составных показателей и распределения удельного веса необходимо определить составные лингвистические переменные. В рамках данной можно выделить одну интегральную лингвистическую переменную и одну зависимую лингвистическую переменную, универсальную для всех частных показателей. Интегральная лингвистическая переменная может быть названа - «Интегральный уровень устойчивости бизнес-процессов деревообрабатывающего предприятия». Значения данной лингвистической переменной могут быть распределены в рамках вещественной оси от 0 до 1, и дифференцированы на пять нечетких подмножеств:

1. Экстремально низкий уровень устойчивости бизнес-процессов деревообрабатывающего предприятия;

2. Низкий уровень устойчивости бизнеспроцессов деревообрабатывающего предприятия;

3. Допустимый уровень устойчивости бизнес-процессов деревообрабатывающего предприятия;

4. Значимый уровень устойчивости бизнеспроцессов деревообрабатывающего предприятия;

5. Высокий уровень устойчивости бизнеспроцессов деревообрабатывающего предприятия.

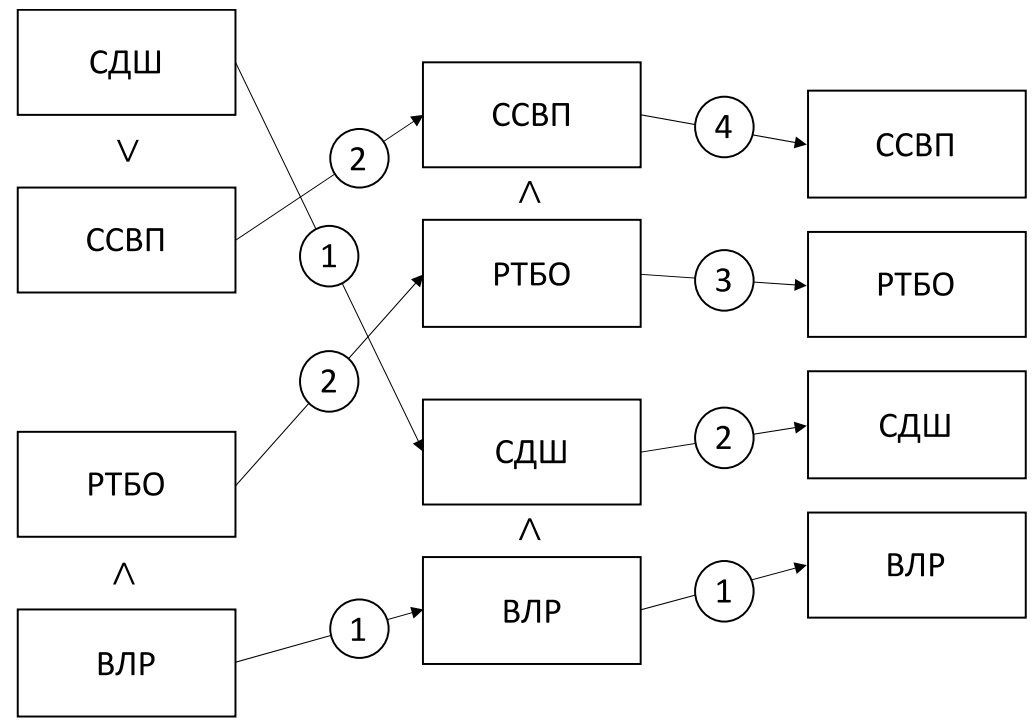

Рисунок 1. Бинарный алгоритм формирования иерархии показателей 


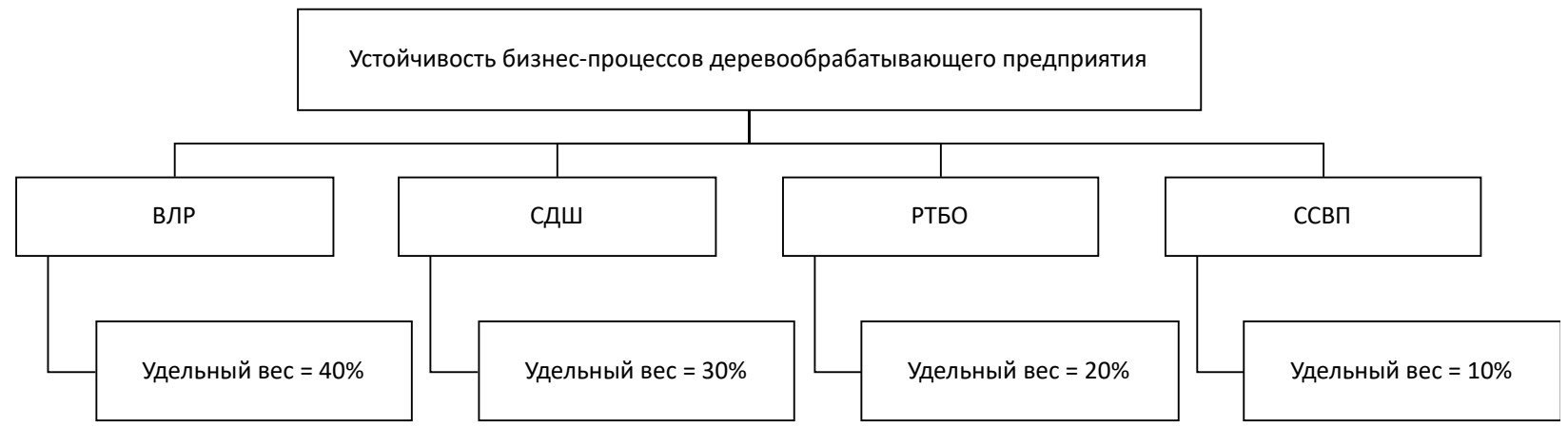

Рисунок 2. Распределение удельного веса между составными показателями устойчивости бизнес-процессов деревообрабатывающего предприятия

В рамках распределения значений лингвистической переменной частных показателей также предлагается выделить пять нечетких подмножеств:

1. Крайне низкое значение показателя;

2. Низкое значение показателя;

3. Типичное значение показателя;

4. Высокое значение показателя;

5. Экстремально высокое значение показателя.

Переход между состояниями лингвистической переменной описывается системой трапециевидных функций принадлежности, представленных в таблице 1.

Приведённые классификаторы могут быть представлены в виде трапециевидных функций принадлежности, где по оси ординат обозначены значения функций принадлежности (от 0 до 1), а по оси абсцисс - термы. При этом верхнее основание трапеции соответствует абсолютной уверенности оценивающего в надежность классификации, а нижнее основание характеризует уверенность в том, что никакие другие значения интервала $(0 ; 1)$ не попадают в выбранное нечеткое подмножество. Боковые грани трапеций отражают колебание суждения оценивающего о принадлежности конкретного отрезка на 01-носителе к тому или иному терму [7].
Имеет место 5 узловых точек: $\{0,1 ; 0,3 ; 0,5$; $0,7 ; 0,9\}$. По результатам расчета каждого из частных показателей, проводится распознавание их значений по критерию $\lambda \mathrm{ij} \in[0 ; 1]$. Данный показатель соотносит значения частных показателей со значениями 01-носителя:

$$
\lambda_{i j}=1-\frac{X_{i}-a_{3}^{*}}{a_{4}^{*}-a_{3}^{*}}
$$

где а3* и а $4 *$ - Т-числа і-го подмножества терм-множества.

По результатам распознавания значений частных показателей, рассчитывается интегральный показатель:

$$
\begin{aligned}
& \text { УБП }=p_{j} \times r_{\text {ВЛР }} \times \lambda_{\text {ВЛР } j}+p_{j} \times r_{\text {СДШ }} \times \lambda_{\text {СДШ } j}+ \\
& +p_{j} \times r_{\text {РтБо }} \times \lambda_{\text {РТБО } j}+p_{j} \times r_{\text {ССВП }} \times \lambda_{\text {ССВП } j}
\end{aligned}
$$

$p_{j}=0,9-0,2 \times(j-1)$

где $\mathrm{j}$ - номер подмножеств базового терм множества

\begin{tabular}{|c|c|c|c|c|c|}
\hline \multirow[b]{2}{*}{ Показатель } & \multicolumn{5}{|c|}{ Т-числа $\{\mathrm{y}\}$ для значений лингвистической переменной } \\
\hline & $\begin{array}{c}\text { Крайне низкое } \\
\text { значение пока- } \\
\text { зателя }\end{array}$ & $\begin{array}{c}\text { Низкое значение } \\
\text { показателя }\end{array}$ & $\begin{array}{c}\text { Типичное значе- } \\
\text { ние показателя }\end{array}$ & $\begin{array}{l}\text { Высокое значе- } \\
\text { ние показателя }\end{array}$ & $\begin{array}{c}\text { Экстремально } \\
\text { высокое значе- } \\
\text { ние показателя }\end{array}$ \\
\hline ВЛР & $(0 ; 0 ; 10 ; 15)$ & 5) & $(20 ; 25 ; 30 ; 35)$ & $(30 ; 35 ; 40 ; 45)$ & $(40 ; 45 ; 100 ; 100)$ \\
\hline СДШ & $(0 ; 0 ; 1.2 ; 3.5)$ & $(1.2 ; 3.5 ; 5.8 ; 8.1)$ & $\begin{array}{c}(5.8 ; 8.1 ; 10.4 \\
12.7)\end{array}$ & $\begin{array}{c}(10.4 ; 12.7 ; 15 ; \\
17.3)\end{array}$ & $(15 ; 17.3 ;+\infty ;+\infty)$ \\
\hline РТБО & $(0 ; 0 ; 30 ; 41)$ & $(30 ; 41 ; 52 ; 63)$ & $(52 ; 63 ; 74 ; 85)$ & $(74 ; 85 ; 96 ; 107)$ & $(96 ; 107 ;+\infty ;+\infty)$ \\
\hline ССВП & $(100 ; 100 ; 100 ; 80)$ & $(100 ; 80 ; 70 ; 60)$ & $(70 ; 60 ; 50 ; 40)$ & $(50 ; 40 ; 30 ; 20)$ & $(30 ; 20 ; 10 ; 10)$ \\
\hline
\end{tabular}

Полученный интегральный показатель распознается в соответствии с выделенными

Таблица 1. Нечетко-множественные классификаторы частных показателей 
терм-множествами и отражает уровень устойчивости бизнес-процессов деревообрабатывающего предприятия Вьетнама. Данный показатель является дополняющим по отношению к показателю результирующей эффективности бизнес- процессов, и в рамках функционального анализа зависимости данных показателей предприятие получает возможность управлять своим воздействием на окружающую среду управляя эффективностью бизнес-процессов.

\section{Библиографический список}

1. Барсков В.В., Белостоикая А.А., Забелин Б. Ф., Конников Е.А. Актуальные вопросы производственного менеджмента в практической деятельности промышленного предприятия // Монография. Казань, 2017.

2. Жогова Е.В., Зайцев А. А., Родионов Д.Г. Инструментальные методы оценки региональной промышленной политики // Российский экономический интернет-журнал. 2019. № 2. С. 35.

3. Заборовская О.В. Социальное предпринимательство как механизм устойчивого развития региона // Экономика и предпринимательство. 2017. № 10-1 (87). С. 455-459.

4. Заборовская О.В., Жогова Е.В. Инструментарий обеспечения инвестиционных процессов реализации региональной промышленной политики // Российский экономический интернет-журнал. 2018. № 4. С. 40.

5. Заборовская О.В., Ниязова С.P. Проблемы и перспективы развития инновационной среды в России // Вестник Российской академии естественных наук (Санкт-Петербург). 2013. № 4. С. 16-20.

6. Игольникова О.С., Копылов А.В. Нечетко-множественная модель оценки технической составляющей инновационного потенциала предприятия // БИЗНЕС. ОБРАЗОВАНИЕ. ПРАВО. ВЕСТНИК ВОЛГОГРАДСКОГО ИНСТИТУТА БИЗНЕСА, (2010), № 3 (13).

7. Игольникова О.С., Санжапов Б.Х. Нечетко-множественная модель оценки финансовой составляющей инновационного потенциала строительной организации // материалы Международной научно-практической конференции, 24 декабря 2010 г., г. Волгоград: в 2-х ч. Ч. II / Волгогр. гос. архит.-строит. ун-т. - Волгоград: ВолгГАСУ, (2010).

8. Клочков Ю.С., Конников Е.А. Трансформация структуры производственной себестоимости на промышленном предприятии в процессе интеграции аддитивных технологий // Известия Самарского научного центра Российской академии наук. 2019. Т. 21. № 1 (87). С. 5-10.

9. Конников Е.А. Нечетко-множественная модель оценки уровня инвестиционной привлекательности интеграции аддитивных технологий в производственный процесс промышленного предприятия // Проблемы современной экономики. 2019. № 2 (70). С. 83-86.

10. Конников Е.А., Алексеев А.А., Метелев П. С., Мокейчев Е.В., Шматко А.Д. Экономика передовых производственных технологий // Казань, (2016).

11. Конников Е.А., Барсков В.В. Цель российской промышленности и результаты ее достижения на современном этапе // Экономика и предпринимательство. 2015. № 11-2 (64). С. 167-170

12. Кошман А.В., Родионов Д.Г. Турбулентность цен на нефть как вызов устойчивости развития нефтяной промышленности в России // Бизнес. Образование. Право. 2020. № 3 (52). С. 69-75.

13. Недосекин А.О. Методологические основы моделирования финансовой деятельности с использованием нечетко-множественных описаний: Дисс... докт. экон. наук / Санкт-Петербургский государственный университет экономики и финансов.- СПб., 2003

14. Родионов Д.Г., Кудрявцева Т.Ю. Механизм и принципы формирования кластерной промышленной политики // Инновации. 2018. № 10 (240). С. 81-87

15. Родионов Д.Г., Моттаева А.Б., Кошман А.В. Устойчивое развитие и инновационная активность хозяйствующих субъектов нефтегазового комплекса // Kant. 2019. № 1 (30). С. 325-330.

16. Чан Тхи Тхань Тхюи. Бизнес процессы на предприятиях деревообрабатывающей промышленности вьетнама / Чан Тхи Тхань Тхюи, С. В. Терещенко // ФЭС: Финансы. Экономика. Стратегия. ISSN 1995-7637. 2018 vol. 15 No. 12. C. $11-17$.

17. Чан Тхи Хай Иен, С.В. Терещенко. Обеспечение сырьем предприятий деревообрабатывающей промышленности Вьетнама как фактор устойчивого развития // ФЭС: Финансы. Экономика. Стратегия. -2018 - № 11 (Том 15).- C.20-26.

18. Чан Тхи Хай Иен. Возможности и перспективы устойчивого развития деревообрабатывающей промышленности Вьетнама / Тхи Хай Иен Чан, С. В. Терещенко // Известия Санкт-Петербургского государственного экономического университета.-2018. - № 5 (113).- С. 36-43. 